\title{
ANALISIS SENYAWA 6-GINGEROL TERHADAP RIMPANG JAHE YANG DIEKSTRAKSI DENGAN METODE LIQUID CHROMATOGRAPHY MASSA SPECTROMETRY (LC-MS)
}

\section{ANALYSIS OF 6-GINGEROL COMPOUNDS GINGER EXTRACTED BY LIQUID CHROMATOGRAPHY MASS SPECTROMETRY (LC-MS) METHOD}

\author{
Mega Trishuta Pathiassana ${ }^{1)} \nabla$, Dina Mariani ${ }^{1)}$, Nurlaila ${ }^{2)}$ \\ 1) Fakultas Teknologi Pertanian, Universitas Teknologi Sumbawa \\ 2) Balai Bioteknologi, Badan Pengkajian dan Penerapan Teknologi (BPPT) \\ Coresponding Author: mega.trishuta@uts.ac.id
}

\begin{abstract}
ABSTRAK
Data BPS 2017, menunjukan bahwa jahe adalah tanaman biofarmaka kelompok rimpang yang mempunyai luas panen paling tinggi, yaitu sebesar 30 ton per tahun dengan kondisi produksi yang relatif stabil. Ekstraksi pada rimpang jahe adalah penyarian zat-zat aktif dari bagian tanaman obat yang bertujuan untuk menarik komponen kimia yang terdapat dalam simplisia yang didasarkan pada perpindahan massa komponen zat padat ke dalam pelarut. Tujuan dari penelitian ini adalah menganalisis pengaruh konsentrasi pelarut terhadap aktivitas senyawa 6-gingerol pada ekstrak jahe dengan metode ekstraksi maserasi menggunakan pelarut etanol berkonsentrasi 30\%, 70\%, dan 96\%. Hasil dari analisa kadar 6gingerol dengan menggunakan LC-MS didapatkan bahwa kandungan tertinggi terdapat pada sampel yang diekstraksi dengan etanol 96\%, yaitu 2,01\%. Sedangkan, kadar terendah terdapat pada etanol 30\%, yaitu 0,64\%. Di lain sisi, sampel jahe yang diekstraksi dengan etanol 70\% memiliki kandungan 6-gingerol sebesar 1,21\%. Hal ini disebabkan oleh semakin pekatnya konsentrasi suatu pelarut, maka akan mengakibatkan semakin tingginya konstanta dielektriknya.
\end{abstract}

Kata Kunci: jahe; 6-gingerol; etanol; shogaol; LC-MS

\section{ABSTRACT}

BPS 2017 data shows that ginger is a rhizome group biopharmaca plant has the highest harvested area as 30 tonnes per year with relatively stable production condition. Extraxtion of ginger rhizome is the extraction of active substances from parts of medicinal plant which aim to attract the chemical components contained in simplicial which are based on the mass transfer of solid components into the solvent. The purpose of this study was to analyze the effect of the solvent concentration on the activity of the 6-gingerol compound in ginger extract with the maceration extraction method using 30\%, 70\%, and $96 \%$ ethanol solvent. The results of the analysis of 6-gingerol levels using LC-MS showed that the highest content was found in the sample extracted with $96 \%$ ethanol, namely $2.01 \%$. Meanwhile, the lowest level was found in 30\% ethanol, namely $0.64 \%$. On the other hand, the ginger sample extracted with $70 \%$ ethanol has a 6-gingerol content of $1.21 \%$. This is due to the higher the concentration of a solvent, the higher the dielectric constant.

Keywords: ginger; 6-gingerol; ethanol; shogaol; LC-MS 


\section{PENDAHULUAN}

Data Badan Pusat Statistik (BPS) 2017, menunjukan bahwa jahe adalah tanaman biofarmaka kelompok rimpang yang mempunyai luas panen paling tinggi, yaitu sebesar 30 ton per tahun dengan kondisi produksi yang relatif stabil. Jahe (Zingiber officinale rosc) juga merupakan salah satu jenis tanaman dalam famili temu-temuan (Zingiberaceae) yang terdiri dari sekitar 1.400 spesies (Washikah, 2016). Nama "Zingiber" sendiri berasal dari Bahasa Sansekerta "Singabera" dan Bahasa Yunani "Ziwngiberi" yang berarti tanduk, karena bentuk rimpang jahe mirip dengan tanduk rusa. Sedangkan, Officinale berarti digunakan dalam farmasi atau pengobatan yang merupakan Bahasa Latin dari “Officina” (Sya'ban, 2013).

Ekstraksi pada rimpang jahe adalah penyarian zat-zat aktif dari bagian tanaman obat. Tujuan dari ekstraksi adalah untuk menarik komponen kimia yang terdapat dalam simplisia yang didasarkan pada perpindahan massa komponen zat padat ke dalam pelarut dimana perpindahan mulai terjadi pada lapisan antar muka, kemudian berdifusi masuk ke dalam pelarut. Optimasi ekstraksi yang dilakukan pada penelitian ini menggunakan variasi konsentrasi etanol sebanyak 30\%, 70\%, dan 96\% untuk mengetahui konsentrasi optimum yang dapat mengekstrak 6- gingerol dari rimpang jahe. Rimpang jahe banyak mengandung minyak atsiri dan oleoresin yang bermanfaat bagi kesehatan, sehingga rimpang memiliki nilai ekonomi.

Berbagai penelitian membuktikan bahwa jahe mempunyai sifat antioksidan dengan beberapa komponen utamanya 6gingerol dan shogaol (Winarti, dkk, 2005). 6-Gingerol pada jahe bersifat antikoagulan yang berfugsi mencegah penggumpalan darah, sehingga mencegah tersumbatnya pembuluh darah yang merupakan penyebab utama stroke dan serangan jantung. Selain itu, 6-gingerol dan shogaol juga mempunyai aktivitas antireumatik. Mengingat manfaat dari senyawa 6gingerol pada jahe, oleh karena itu perlu dilakukannya pengaruh proses pengeringan terhadap aktivitas senyawa 6gingerol pada ekstrak jahe dengan metode ekstraksi maserasi menggunakan pelarut etanol berkonsentrasi 30\%, 70\%, dan 96\%.

\section{METODE PENELITIAN}

\section{Bahan dan Alat}

Bahan yang digunakan dalam penelitian ini adalah jahe, ethanol dengan konsentrasi $30 \%, 70 \%, 96 \%$, aquades, kertas saring, dan aluminium foil. Sedangkan alat yang digunakan dalam penelitian ini, yaitu timbangan analitik, blender, vakum konsentrator, alat sentrifugasi, rotary evavorator, mesin 
shaker, timbangan, oven, loyang, moisture analiyzer, LC-MS, pisau, erlenmeyer, spatula, pipet tetes, gelas ukur, mikrovipet, eppendorf, porteks, dan tabung falcon.

\section{Prosedur Penelitian}

\section{Persiapan Sampel dan Uji Kadar Air}

Tahapan persiapan sampel dan uji kadar air sebagai berikut : jahe dicuci sampai bersih, kemudian ditiriskan sampai kering. Setelah kering jahe ditimbang kemudian, jahe diiris membujur dengan ketebalan 0-2 mm. Jahe yang sudah diiris, lalu dikeringkan pada oven dengan suhu $60^{\circ} \mathrm{C}$ sampai diperoleh kadar air $\pm 12 \%$. Setelah itu, jahe ditimbang kembali untuk membandingkan bobot sampel jahe sebelum pengeringan dengan bobot sampel jahe setelah pengeringan. Pengujian kadar air pada penelitian ini dilakukan dengan menggunakan alat moisture analiyzer $\mathrm{S} / \mathrm{N}$ P1017391.

\section{Ekstraksi Jahe}

Tahapan ekstraksi jahe sebagai berikut : jahe yang sudah kering, kemudian dihaluskan menggunakan blender. Sampel jahe yang sudah dihaluskan mempunyai bobot 52,8 gram, kemudian ditimbang menggunakan 3 buah erlenmeyer masingmasing sampel berisi 17 gram. Selanjutnya ditambahkan larutan etanol dengan variasi konsentrasi $30 \%$, 70\%, dan 96\% masingmasing $150 \mathrm{ml}$, dan diulang sebanyak 3 kali. Sampel jahe yang sudah dilarutkan dengan etanol, kemudian diaduk menggunakan mesin pengocok dengan kecepatan 3.500 rpm selama 8 jam. Larutan yang telah dikocok, lalu disaring dan dimasukan ke dalam valkon. Setelah itu, disentrifugasi dengan kecepatan 3.000 rpm selama 10 menit. Sampel yang telah disentrifugasi, lalu disaring kembali dengan kertas saring kemudian sampel didestilasi menggunakan alat rotary evaporator. Sampel yang sudah didestilasi, lalu dikeringkan menggunakan alat vakum konsetrator.

\section{Analisis LC-MS}

Tahapan analisis LC-MS sebagai berikut : sampel yang sudah dikeringkan, ditimbang menggunakan eppendorf dengan berat 0,0010 gram. Sampel yang sudah ditimbang, kemudian dilarutkan dengan methanol sebanyak $1 \mathrm{ml}$ ke dalam eppendof dan dilakukan analisa menggunakan LC-MS.

\section{Kondisi Alat LC (Liquid}

\section{Chromatography)}

Kondisi alat LC saat analisis, diantaranya berkaitan dengan fase gerak (A) ultrapure water dengan asam format $0,1 \%$; (B) asetonitril dengan asam format $0,1 \%$. Sistem gradient ditunjukan oleh Tabel 1, laju aliran fase gerak $0,3 \mathrm{ml} / \mathrm{min}$ dengan rentang waktu analisis selama 9 
menit, volume injeksi $5 \mu$ l, suhu kolom

$40^{\circ} \mathrm{C}$ dan temperatur sampel $10^{\circ} \mathrm{C}$.

Tabel 1. Sistem Gradient Alat LC

\begin{tabular}{cccc}
\hline Min & (\%) A & (\%) B & Curve \\
\hline 0,0 & 95 & 5 & - \\
\hline 1,0 & 95 & 5 & 6 \\
\hline 6,0 & 0 & 100 & 6 \\
\hline 7,0 & 0 & 100 & 6 \\
\hline 7,5 & 95 & 5 & 6 \\
\hline 9,0 & 95 & 5 & 6 \\
\hline
\end{tabular}

Kondisi Alat MS (Mass Spectrometry)

Waktu analisis 9 menit; lock spray leucine encephalin; suhu probe API $20^{\circ} \mathrm{C}$; source es dengan capillary 2,00; sample cone 40 dan extraction cone 2,0; polaritas positif temperatur sumbernya $120^{\circ} \mathrm{C}$ dan temperatur desolvation $350^{\circ} \mathrm{C}$. TOF MS low mass $=100 \mathrm{Da}$; high mass $=1.000$ Da; scanning condition: scan time: $1 \mathrm{sec}$; data format: continuum.

\section{HASIL DAN PEMBAHASAN}

\section{Hasil Rendemen Serbuk Simplisia Jahe}

Hasil bobot simplisia dan rendemen simplisia ditunjukkan oleh Tabel 2. Berdasarkan Tabel 2, bobot jahe sebelum dicuci adalah 443,9 gram. Setelah dicuci dan ditiriskan, bobotnya menjadi 395,8 gram. Proses pengeringan jahe dilakukan dengan pengeringan oven selama 5 hari selama 8 jam setiap harinya. Bobot akhir serbuk simplisia jahe yang diperoleh adalah sebesar 51,68 gram dengan hasil rendemen simplisia jahe sebanyak $13,05 \%$.

Sebelumnya, jahe dijemur terlebih dahulu di bawah sinar matahari. Pada prinsipnya, hal ini dilakukan untuk menguapkan air yang terkandung di dalam bahan pangan. Kadar air jahe yang diperoleh pada sampel jahe emprit adalah sebesar 6,31\%. Nilai Standar Nasional 013393 Tahun 1994, menyebutkan bahwa kadar air pada rimpang jahe kering adalah maksimum 12\%. Pengujian kadar air penting dilakukan untuk menentukan daya simpan dari suatu bahan. Merdhikawati (2006) mengemukakan bahwa kandungan air pada sampel jahe mempengaruhi pelarutan senyawa yang terekstrak. Semakin rendah kandungan air pada sampel, akan semakin maksimal proses ekstraksinya. 
Tabel 2. Bobot Awal dan Bobot Akhir Jahe Setelah Pengeringan

\begin{tabular}{|c|c|c|c|c|c|}
\hline $\begin{array}{l}\text { Bobot } \\
\text { awal } \\
\text { (g) }\end{array}$ & $\begin{array}{c}\text { Bobot } \\
\text { Setelah } \\
\text { dicuci (g) }\end{array}$ & $\begin{array}{c}\text { Waktu } \\
\text { pengeringan } \\
\text { (jam/hari) }\end{array}$ & $\begin{array}{c}\text { Lama } \\
\text { pengeringan } \\
\text { (hari) }\end{array}$ & $\begin{array}{c}\text { Bobot } \\
\text { simplisia } \\
\text { (g) }\end{array}$ & $\begin{array}{c}\text { Rendemen } \\
\text { simplisia } \\
(\%)\end{array}$ \\
\hline 443,9 & 395,8 & 8 & 5 & 51,68 & 13,05 \\
\hline
\end{tabular}

\section{Hasil Rendemen Ekstrak Jahe}

Pembuatan ekstrak mengunakan pelarut etanol dengan konsentrasi $30 \%$, 70\%, dan 96\%. Ekstrak kental yang diperoleh berwarna coklat kehitaman, warna khas jahe, dan masih tercium aroma pelarut. Hasil bobot ekstrak dan rendemen ekstrak ditunjukkan oleh Tabel 3.

Hasil penelitian menunjukkan rendemen ekstrak yang terbesar didapat pada konsentrasi 30\% dengan hasil bobot ekstrak sebesar 2,97 gram dan hasil rendemen ekstrak sebesar 17,38\%. Menurut Fatiha, dkk (2012), jenis dan polaritas pelarut sangat mempengaruhi rendemen senyawa kimia yang dihasilkan, dimana rendemen oleoresin jahe yang dihasilkan dan kandungannya, tergantung pada bahan baku dan pelarut yang digunakan, serta kondisi ekstraksi.

\section{Hasil Analisa Menggunakan LC-MS}

Hasil penelitian menunjukkan sampel ekstrak jahe dengan konsentrasi pelarut $30 \%$ etanol didapatkan hasil kromotogram 6-gingerol pada waktu retensi 4,56 menit dengan luas area 2.842. Kromatogram sampel oven $30 \%$ etanol dapat dilihat pada gambar 1.

Tabel 3. Hasil Bobot Ekstrak dan Rendemen Ekstrak

\begin{tabular}{cccc}
\hline Ekstrak & $\begin{array}{c}\text { Bobot Simplisia } \\
(\text { gram })\end{array}$ & $\begin{array}{c}\text { Bobot Ekstrak } \\
(\text { gram })\end{array}$ & $\begin{array}{c}\text { Rendemen } \\
\text { Ekstrak (\%) }\end{array}$ \\
\hline Etanol 30\% & 17,09 gram & 2,97 gram & $17,38 \%$ \\
\hline Etanol 70\% & 17,10 gram & 2,06 gram & $12,05 \%$ \\
\hline Etanol 96\% & & & \\
\hline
\end{tabular}




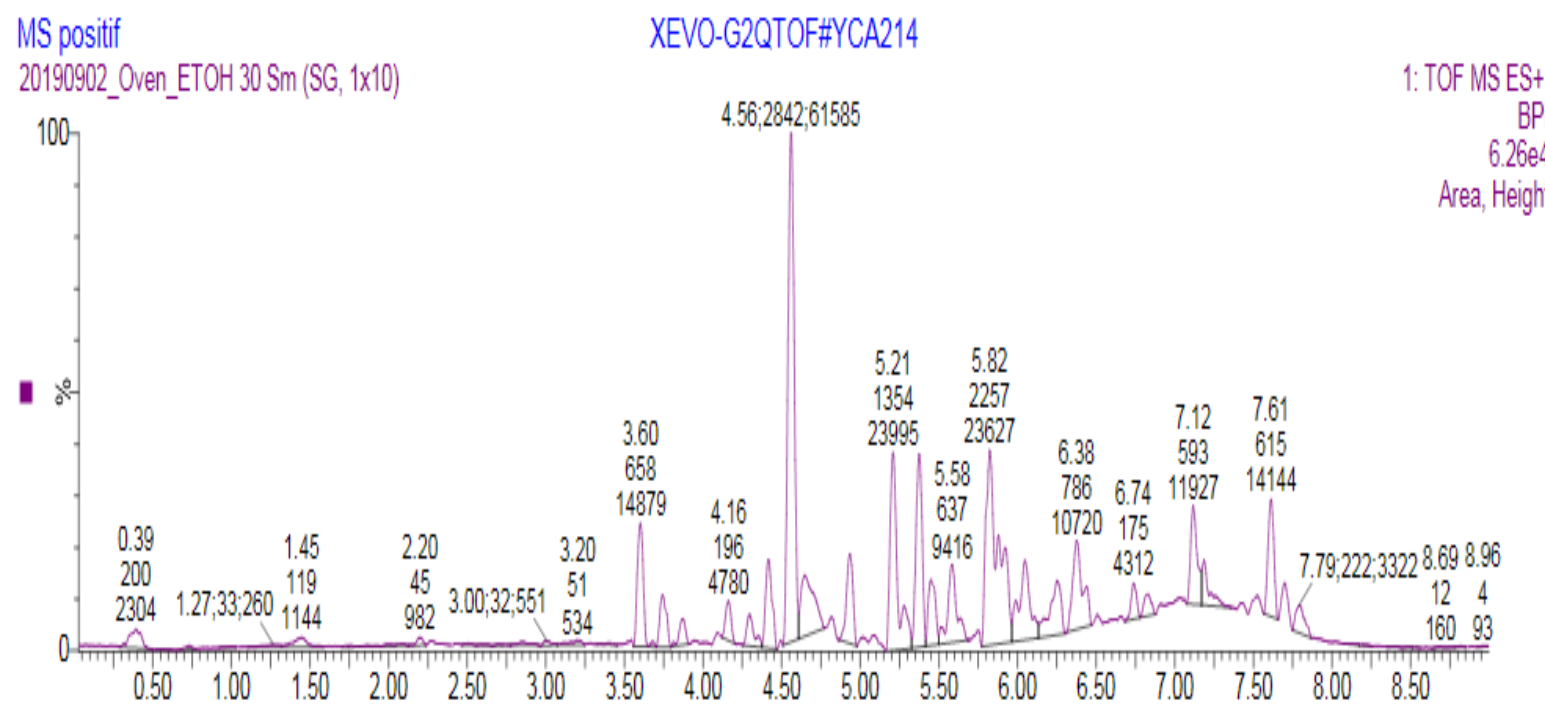

Gambar 1. Kromatogram Ekstrah Jahic dengan Konsentrasi Etanol 30\%

Sampel ekstrak jahe dengan konsentrasi pelarut $70 \%$ etanol didapatkan hasil kromotogram 6-gingerol pada waktu retensi 4,56 menit dengan luas area 4.920 . Kromatogram sampel oven $70 \%$ etanol dapat dilihat pada gambar 2.
Sampel ekstrak jahe dengan konsentrasi pelarut $96 \%$ etanol didapatkan hasil kromotogram 6-gingerol pada waktu 4,59 menit dengan luas area 10.688 . Kromatogram sampel oven $96 \%$ etanol dapat dilihat pada gambar 3 .

\section{MS positif}

2019090___ven_ETOH 70 Sm (SG, 1x10)

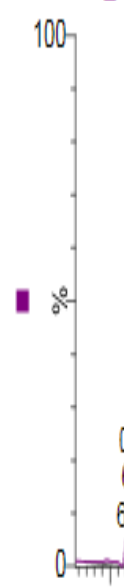

XEVO-G2QTOF\#YCA214

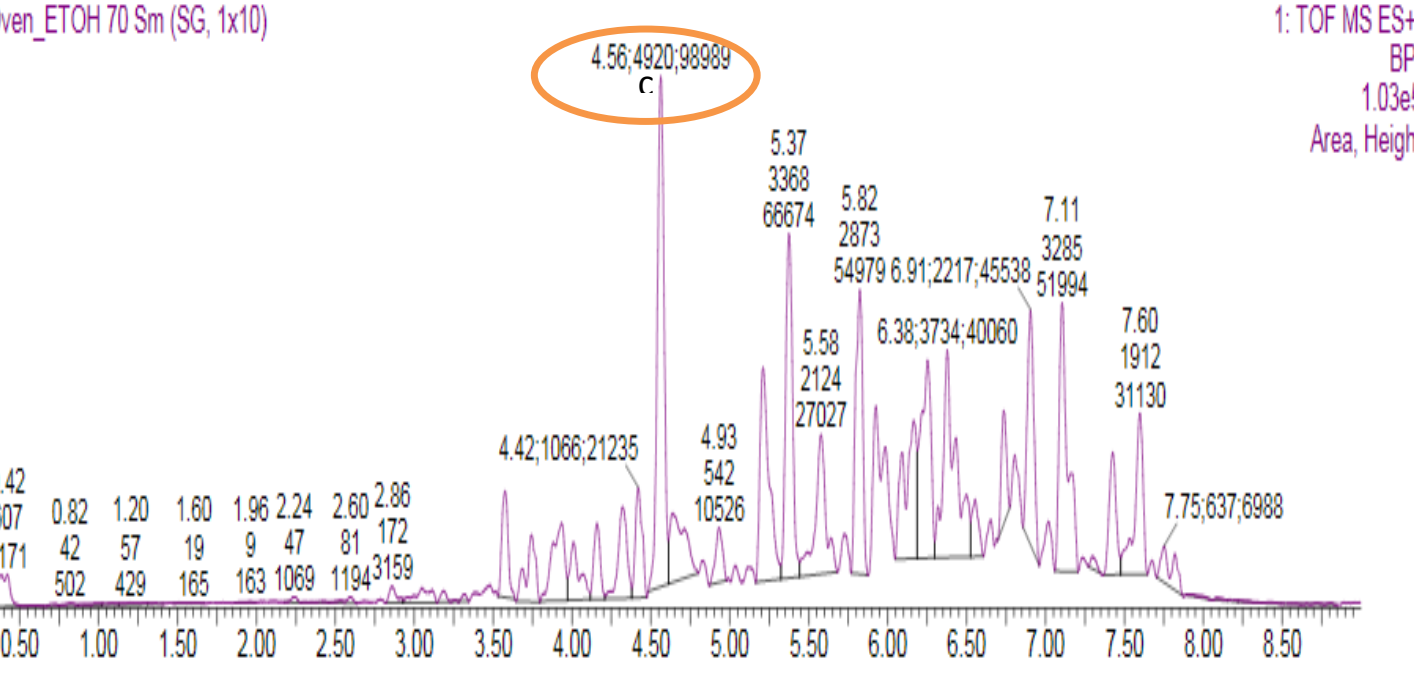

Gambar 2. Kromatogram Ekstrak Jahe dengan Konsentrasi Etanol 70\% 
MS positif

20190003__ven__ETOH 96 __lang Sm $(S G, 1 \times 10)$

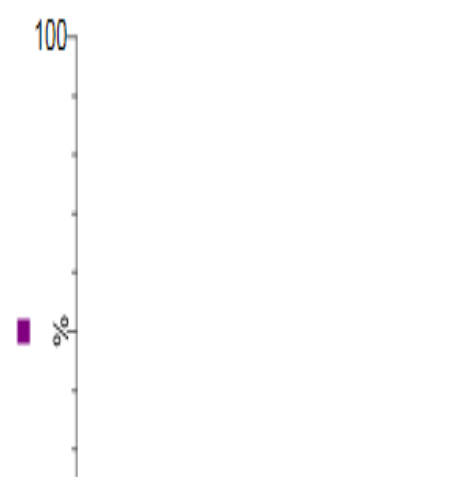

XEVO-G2QTOF\#YCA214

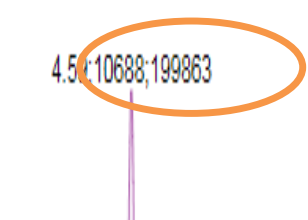

1:TOF MSES+

BPI

Area, Height

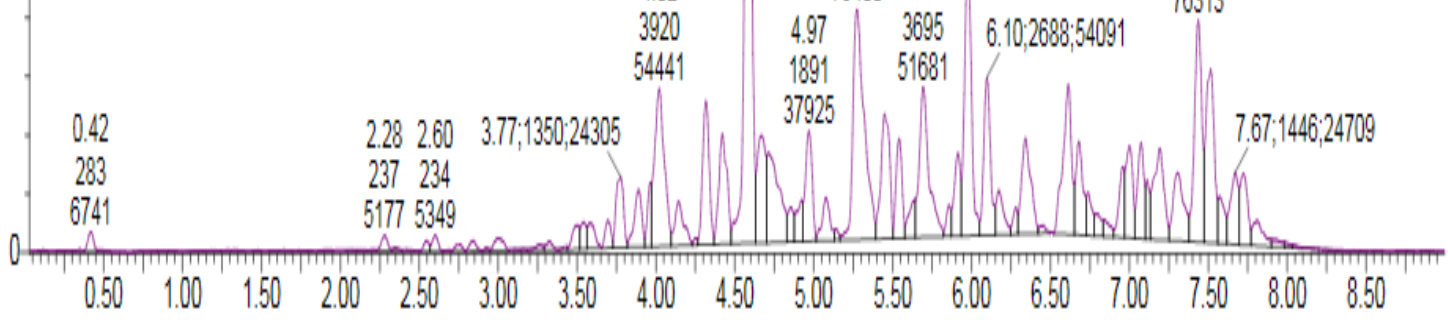

Gambar 3. Kromatogram Ekstrak Jahe dengan Konsentrasi Etanol 96\%

Berdasarkan data dari gambar 3 diperoleh kadar 6-gingerol tertinggi terdapat pada pelarut etanol konsentrasi 96\% dengan persentase kadar 6-gingerol sebesar 2,01\% dibandingkan dengan pelarut etanol konsentrasi $70 \%$ dan $30 \%$. Hasil persentase kadar 6-gingerol pada konsentrasi $70 \%$ sebesar $\quad 1,21 \%$ dan konsentrasi $\quad 30 \% \quad$ sebesar $\quad 0,64 \%$. Berdasarkan hasil penelitian Lee (2007), diketahui bahwa waktu, metode, dan pelarut yang digunakan untuk pengekstraksi berbeda kepolarannya mempengaruhi persentase kadar senyawa 6-gingerol yang didapat.

Kadar 6-gingerol dihasilkan lebih tinggi pada konsentrasi pelarut etanol $96 \%$ dibandingkan dengan konsentrasi pelarut etanol $70 \%$ dan konsentrasi pelarut etanol $30 \%$. Hal ini disebabkan oleh semakin pekatnya konsentrasi suatu pelarut, maka akan mengakibatkan semakin tingginya konstanta dielektriknya. Sehingga, senyawa 6-gingerol lebih berikatan pada etanol dan bukan pada air. Hal ini dikarenakan metode ekstraksi maserasi digunakan dengan cara dingin. 6-gingerol tidak dapat terdekomposisi menjadi shogaol, di mana 6-shogaol merupakan dehidrasi dari gingerol. Perubahan bentuk gingerol selama proses pemanasan akan membentuk shogaol (Wohlmuth, dkk, 2005). Berdasarkan data tersebut dapat disimpulkan bahwa pelarut etanol konsentrasi 96\% merupakan pelarut yang paling optimal untuk mengekstrak senyawa 6-gingerol pada rimpang jahe.

\section{KESIMPULAN}


Hasil dari analisa kadar 6-ngingerol dengan menggunakan LC-MS didapatkan bahwa kandungan tertinggi terdapat pada sampel yang diekstraksi dengan etanol 96\%, yaitu 2,01\%. Sedangkan, kadar terendah terdapat pada etanol $30 \%$, yaitu 0,64\%. Di lain sisi, sampel jahe yang diekstraksi dengan etanol 70\% memiliki kandungan 6-gingerol sebesar 1,21\%. Hal ini disebabkan oleh semakin pekatnya konsentrasi suatu pelarut, maka akan mengakibatkan semakin tingginya konstanta dielektriknya.

\section{DAFTAR PUSTAKA}

BPS. 2017. Statistik Pertanian. www.bps.go.id. Diakses: 8 September 2019.

Fatiha, M.F. 2012. Kajian Karakteristik Oleoresin Jahe Berdasarkan Ukuran dan Lama Perendaman Serbuk Jahe dalam Etanol. Skripsi Jurusan Teknologi Hasil Pertanian. Surakarta.

Hafsoh. 2008. Kajian Tingkat Kerusakan Minyak Pada Jenang Kudus dengan Penambahan Ekstrak Jahe Selama Penyimpanan. Skripsi Jurusan Teknologi Hasil Pertanian. Surakarta.

Lee, S., Khoo, C., Halstead, C.W., Huynh, T., and Bensoussan, A. 2007. Liquid Chromatographic Determination of 6-, 8-, 10gingerol, and 6-shogaol in Ginger (Zingiber officinale) as the Herb and Dried Aqueous Ekstract. Journal of AOAC International. Vol. 90, No. 5.

Merdhikawati, D. 2006. Perbandingan Teknik Ekstraksi dalam Analisis Gingerol pada Jahe Merah (Zingiber officinale, Roscoe).
[Skripsi]. Universitas Nusa Bangsa, Bogor.

Munir. 2012. Analisis Kandungan Fenol Total Jahe (Zingiber officinale Roscoe). Fakultas Kedokteran. Universitas Indonesia. Depok.

Qoyyimah., P. 2012. Budidaya Tanaman Jahe. BPPP. Balai Penelitian Tanaman Obat dan Aromatika.

Setiawan. 2005. Antioksidan Ekstrak Jahe Merah ((Zingiber officinale, Roscoe) dengan Metode Diena Terkonjugasi pada Minyak Kedelai. [Skripsi]. Universitas Nusa Bangsa. Bogor.

Setiawan. 2005. Pemilihan Metode Pemisahan untuk Penentuan Konsentrasi Gingerol dan Pola Respon Fourier Transform Infrared pada Rimpang Jahe Emprit (Zingiber officinale, Roscoe). [Tesis]. Institut Pertanian Bogor.

Sudarma. 2003. Pengaruh Ukuran Bahan dan Lama Ekstraksi Terhadap Rendemen dan Mutu Oleoresin Lada Enteng. Skripsi S-1. Fateta IPB. Bogor.

Sudarmadji. 2003. Kajian Pengaruh Jumlah Pelarut dan Lama Ekstraksi Rimpang Kencur Terhadap Rendemen dan Mutu Oleoresin Kencur. Skripsi S-1. Fateta IPB. Bogor.

Sya'ban, M.F. 2013. Jahe, Kandungan dan Manfaatnya. Makalah Kimia. Universitas Negeri Yogyakarta. Yogyakarta.

Washikah. 2016. Tumbuhan Zingeberaceae sebagai Obatanobatan. Jurnal Serambi Saintia, Vol. IV, No. 1, pp 35-43, ISSN: 2337-9952.

Winarti, C., Nurdjanah, N. 2005. Peluang Tanaman Rempah dan Obat sebagai Sumber Pangan Fungsional. Jurnal Litbang Pertanian, 24 (2). Balai Penelitian dan Pengembangan Pascapanen Pertanian. 
Wohlmuth, H., Leach, D.N., Smith, M.K., Myers, S.P. 2005. Gingerol Content of Diploid and Terpenoid
Clones of Ginger (Zingiber officinale Roscoe). J. Agric. Food Chem. 53: 5772-5778. 